\title{
ANÁLISE DA RELAÇÃO DO RISCO DE QUEDAS COM A COGNIÇÃO E POSTURA ESTÁTICA NO ENVELHECIMENTO
}

Caroline Fagundes; Universidade Feevale; caroline@espacotao.net.br; Geraldine Alves dos Santos; Universidade Feevale; geraldinesantos@feevale.br

\section{RESUMO}

Introdução: $\mathrm{O}$ idoso com comprometimento da cognição pode apresentar déficits de mobilidade, lentificação de movimentos, alterações comportamentais e menor tempo de reação frente aos desequilíbrios, predispondo-o a quedas. Além disso, com o envelhecimento ocorre a redução da flexibilidade das articulações, resultando em desvios posturais e limitação da mobilidade do idoso, dificultando a manutenção do equilíbrio estático e da marcha segura. Objetivo: Analisar a relação do risco de quedas com o desempenho cognitivo e postura estática no envelhecimento. Método: Participaram dessa pesquisa 107 sujeitos, com idade entre 60 e 89 anos, distribuídos em 2 grupos: o primeiro formado por 54 indivíduos praticantes de hidroginástica e o segundo composto por 53 idosos participantes de um programa de informática. Para a coleta de dados os seguintes instrumentos foram utilizados: Mini Exame do Estado Mental, Escala de Eficácia de Quedas, Escala de Equilíbrio de Berg e Postural Assessment Software (SAPO). Resultados: Constatou-se bom desempenho cognitivo, baixo risco de queda e alterações posturais dentro da normalidade. Além disso, observou-se que o risco de quedas está diretamente relacionado com o ângulo da cifose torácica e ângulo do tornozelo. Também foi identificada relação indireta do risco de quedas com a auto eficácia de quedas e alinhamento vertical da cabeça (R2: 0,367). Conclusão: Observou-se relação significativa entre o risco de quedas, cognição, e postura estática em pessoas idosas. Baseado nos achados do presente estudo é possível elaborar medidas de prevenção a quedas em idosos.

Palavras-chave: Cognição; Idosos; Postura estática; Quedas. 